\title{
High-Energy Electron Transfer Dissociation (HE-ETD) Using Alkali Metal Targets for Sequence Analysis of Post-Translational Peptides
}

\author{
Shigeo Hayakawa, ${ }^{a}$ Shinya Matsumoto, ${ }^{a}$ Mami Hashimoto, ${ }^{a}$ \\ Kenichi Iwamoto, ${ }^{a}$ Hirofumi Nagao, ${ }^{\mathrm{b}}$ Michisato Toyoda, ${ }^{\text {, }}$ \\ Yasushi Shigeri, ${ }^{\mathrm{c}}$ Michiko Tajiri, ${ }^{\mathrm{d}}$ and Yoshinao Wada ${ }^{\mathrm{d}}$ \\ a Department of Chemistry, Graduate School of Science, Osaka Prefecture University, Sakai, Osaka, Japan \\ ${ }^{\mathrm{b}}$ Department of Physics, Graduate School of Science, Osaka University, Toyonaka, Osaka, Japan \\ ${ }^{c}$ National Institute of Advanced Industrial Science and Technology, Ikeda, Osaka, Japan \\ ${ }^{\mathrm{d}}$ Osaka Medical Center and Research Institute for Maternal and Child Health, Izumi, Osaka, Japan
}

Post-translational modifications (PTMs) of proteins are important in the activation, localization, and regulation of protein function in vivo. The usefulness of electron capture dissociation (ECD) and electron-transfer dissociation (ETD) in tandem mass spectrometry (MS/MS) using low-energy (LE) trap type mass spectrometer is associated with no loss of a labile PTM group regarding peptide and protein sequencing. The experimental results of high-energy (HE) collision induced dissociation (CID) using the Xe and Cs targets and LE-ETD were compared for doubly-phosphorylated peptides TGFLT(p)EY(p)VATR (1). Although HE-CID using the Xe target did not provide information on the amino acid sequence, HE-CID using the Cs target provided all the z-type ions without loss of the phosphate groups as a result of HE-ETD process, while LE-ETD using fluoranthene anion gave only z-type ions from $z_{5}$ to $z_{11}$. The difference in the results of HE-CID between the Xe and Cs targets demonstrated that HE-ETD process with the Cs target took place much more dominantly than collisional activation. The difference between HE-ETD using Cs targets and LE-ETD using the anion demonstrated that mass discrimination was much weaker in the high-energy process. HE-ETD was also applied to three other phosphopeptides YGGMHRQEX(p)VDC (2: $X=S, 3: X=T, 4: X=Y)$. The HE-CID spectra of the doubly-protonated phosphopeptides $\left(=[\mathrm{M}+2 \mathrm{H}]^{2+}\right)$ of 2,3 , and 4 using the $C_{s}$ target showed a very similar feature that the c-type ions from $c_{7}$ to $c_{11}$ and the $\mathrm{z}$-type ions from $\mathrm{z}_{7}$ to $\mathrm{z}_{11}$ were formed via $\mathrm{N}-\mathrm{C} \alpha$ bond cleavage without a loss of the phosphate group. (J Am Soc Mass Spectrom 2010, 21, 1482-1489) (c) 2010 American Society for Mass Spectrometry

$\mathrm{P}$ ost-translational modifications (PTMs) of proteins are important in vivo, especially, reversible protein phosphorylation, principally localized on serine, threonine, or tyrosine residues, is one of the most important and well-studied. Phosphorylations play crucial roles in the regulation of cellular processes such as cell cycle, cell growth, apoptosis, and signal transduction [1,2]. Although the mass analysis of phosphorylated proteins and peptides has become possible since the development of electrospray ionization (ESI) technique [3], the determination of phosphorylated positions has not yet been achieved by the most popular dissociation method, namely, a low-energy collisionally activated dissociation (LE-CAD) performed by using the tandem mass spectrometry (MS/

Address reprint requests to Professor S. Hayakawa, Department of Chemistry, Graduate School of Science, Osaka Prefecture University, 1-1 Gakuencho, Naka-ku, Sakai, Osaka 599-8531, Japan. E-mail: hayakawa@c.s.osakafuu.ac.jp
MS) [4]. Electron capture dissociation (ECD) using a Fourier transform ion cyclotron resonant mass spectrometer (FT-ICR-MS) [5-8] and electron-transfer dissociation (ETD) using a linear trap mass spectrometer [9, 10] can provide information on c- and z-type ions [11, 12] produced via $\mathrm{N}-\mathrm{C} \alpha$ backbone cleavage with no loss of labile PTM groups, such as phosphate and sulfate groups $[13,14]$. The $\mathrm{N}-\mathrm{C} \alpha$ backbone cleavage is different from other fragmentations brought about by collisional activation or infrared photoexcitation of closedshell cations [15]. The charge reduced peptide cation radicals formed by ECD and ETD are known to dissociate at various positions via the low-energy transitionstate for bond cleavage [16-20]. Differences between ECD and ETD are also reported [15, 21, 22] .

Charge inversion mass spectrometry using alkali metal targets [23-29] for singly protonated peptides and amino acids provided the information of the radical traps in the dissociation mechanism of the charge 
reduced peptides [28, 30, 31]. N-C $\alpha$ bond cleavages induced by electron-transfer processes of multiply charged peptides upon collision with alkali metals have been reported by Hvelplund and coworkers [32-37]. The mechanism of HE-ETD of doubly-charged ions on collision with alkali metal targets were elucidated by using thermometer molecules $\mathrm{W}(\mathrm{CO})_{6}[38,39]$. Recently, the result of electron-transfer process in the HE collision of the doubly-protonated phosphopeptides $\left[(\text { YGGMHRQET(p)VDC) }+2 \mathrm{H}]^{2+}\right.$ (1) with the Cs target has been reported [40]. The component of (MHRQET (p)VDC) corresponds to an autophosphorylation site of $\mathrm{Ca}^{2+} /$ calmodulin (CaM)-dependent protein kinase II (CaMKII), phospho-CaMKII (281-289), which was a physiologically important sequence in learning and memory [41, 42]. Two phosphopeptides in which $\mathrm{T}(\mathrm{p})$ was replaced by $S(p)$ or $Y(p)$ are used in this work. A synthetic peptide TGFLT(p)EY(p)VATR (Erk2) is utilized as a representative of doubly-phosphorylated peptide. MAP kinase (mitogen-activated protein kinase, Erk2) is an important protein kinase in a cellular response [43]. MAP kinase is phosphorylated by activated MAP kinase (MEK) at Thr183 and Tyr 185, leading to activation of the kinase. TGFLT(p)EY(p)VATR corresponds to these phosphorylation sites.

In the present work, HE-ETD using the Cs target was applied to the phosphopeptides, which have two phosphorylation sites and different amino acid residues phosphorylated. A large difference of the spectra obtained for HE-ETD using a Cs target compared with those obtained for HE-CAD using a Xe target and obtained for LE-ETD using a negative ion demonstrated the superiority of HE-ETD when Cs is used as a target.

\section{Experimental}

\section{Sample Preparation}

Phosphopeptides YGGMHRQES(p)VDC (1), YGGMH RQET(p)VDC (2), YGGMHRQEY(p)VDC (3), and TGF LT(p)EY(p)VATR (4), were synthesized by use of a Shimadzu PSSM-8 automated peptide synthesizer according to the method of Wakamiya et al. [44] and the obtained pep- tides were purified by reversed-phase high-performance liquid chromatography [45]. The identity and purity of the peptides were confirmed by matrix-assisted laser desorption/ionization (MALDI)-TOF MS using a Voyager DE-STR mass spectrometer (Applied Biosystems, Foster, CA, USA) and $\alpha$-cyano-4-hydroxycinammic acid as a matrix. Each of those peptides was electrosprayed from a solution of 1:1 water:methanol containing $2 \%$ acetic acid by volume.

\section{Tandem Mass Spectrometry for High-energy Collision Induced Dissociation (HE-CID), Which Included Collisionally Activated Dissociation and Electron Transfer Dissociation}

Mass-selected doubly-protonated sample ions were collided with either a Xe or a Cs targets, and resulting singly- and doubly-charged ions were mass-analyzed by using a tandem mass spectrometry (MS/MS) instrument. In the present instrument, a quadrupole lens doublet was newly mounted and the conversion dynode of the detector was changed from the flat type used in the previous instrument $[39,46]$ to a curved type. A schematic of the modified instrument is shown in Figure 1. Doubly-protonated peptide ions were generated by an electrospray ionization source (JEOL, Tokyo, Japan, MS-API10/BU). A sample solution was infused into an electrospray emitter at a flow rate of 30 $\mu \mathrm{L} / \mathrm{min}$. The doubly-protonated ions were accelerated to a kinetic energy of $10 \mathrm{keV}$ by applying an accelerating voltage of $5 \mathrm{kV}$. Mono-isotopic ions were mass selected by a JEOL JMS-HX110 double-focusing mass spectrometer (MS-I). The mass-selected precursor ions were led to a $3.7 \mathrm{~cm}$ long collision cell located at the exit of MS-I. Cs vapor was introduced into the collision cell from a reservoir through a ball valve. The temperatures of the collision cell, the ball valve, and the reservoir were adjusted to control the density of Cs vapor in the collision cell. The CID spectra using the Cs target were measured under the transmittance of $35 \%$ by controlling the temperature, under which the condition of single collision with the target was presumably

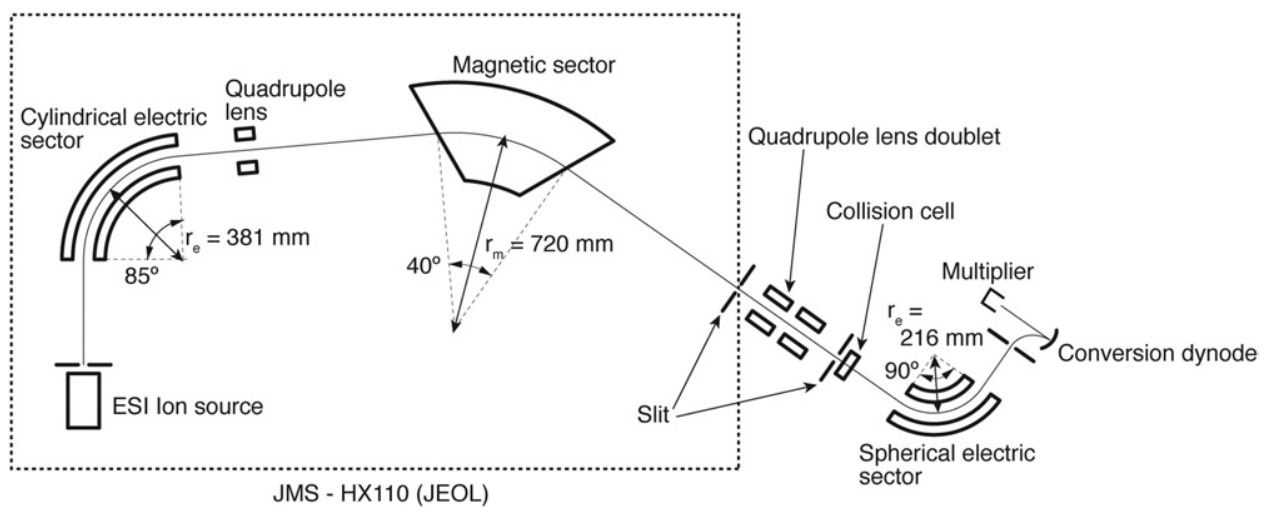

Figure 1. Schematic of the MS/MS instrument modified by adding the quadrupole lens and by upgrading the conversion dynode. 
achieved, as discussed in the previous paper [40]. The singly- and doubly-charged positive ions were massanalyzed by a spherical electrostatic analyzer of a central radius of $216 \mathrm{~mm}$ (MS-II). The flight length between the exit of the target chamber and the entrance of the MS-II was $230 \mathrm{~mm}$. The mass-analyzed ions were detected by a post-acceleration secondary-electron multiplier. The quadrupole lens doublet mounted between the JMS-HX110 and the collision cell improved the efficiency of ion transmission into the collision cell about 10 times. By applying $11 \mathrm{kV}$ to the curved type conversion dynode, ion intensities of charge reduced fragment ions of both lower and higher masses than those of the precursor ions were significantly increased [46].

By changing the collision cell, the Xe gas target was introduced in a collision cell of the same size as was used for the alkali metal target. The density of the Xe gas was controlled by means of a variable-leak valve (Swagelok, Solon, OH, USA, SS-22RS2). The target gas pressure was directly measured by means of a capacitance manometer (MKS, Andover, MA, USA, Baratron 127AA-00001B) attached to the collision cell by a pipe of a $26 \mathrm{~mm}$ i.d. with a gas conductance of $11 \mathrm{dm}^{3} \mathrm{~s}^{-1}$. The CID spectra for the Xe target were measured at the gas pressure of $0.45 \mathrm{~Pa}$ in the collision cell, which allowed a transmittance of about $50 \%$. The scattering cross section was estimated to be $1.6 \times 10^{-15} \mathrm{~cm}^{2}$ from the target pressure and the transmittance. This value for the Xe target was four times larger than that of the $\mathrm{W}(\mathrm{CO})_{6}^{2+}$ ion on collision with the Ar target [38]. The pressures measured by ionization gauges mounted on both the vacuum chamber and on MS-II were less than $6 \times 10^{-5}$ $\mathrm{Pa}$ when the target gas was not supplied.

\section{Measurement of Low-Energy ETD Spectra}

Low-energy spectra were measured with a Finnigan LTQ XL (ThermoFisher Scientific, Waltham, MA, USA). A relevant sample was introduced into a nano-spray ion source. For the low-energy ETD measurements, doubly-protonated phosphopeptides were collided with fluoranthene anion formed by chemical ionization at a collision energy of $35 \mathrm{eV}$ in the period of $200 \mathrm{~ms}$. To improve the resolution, $\mathrm{He}$ gas was introduced in the linear trap. The spectrum shown in the present paper was accumulated 200 times.

\section{Results and Discussion}

\section{Collision Induced Dissociation (CID) Spectra \\ Using the Xe and Cs Targets and ETD \\ Spectrum Using Fluoranthene Anion of Doubly-Phosphorylated Peptide 1}

Figures $2 \mathrm{a}$ and $\mathrm{b}$ show CID spectra of the doubly charged phosphopeptide [(TGFLT(p)EY(p)VATR) + $2 \mathrm{H}]^{2+}\left(=[\mathrm{M}+2 \mathrm{H}]^{2+}, \mathbf{1}\right)$ with the Xe (Figure 2a) and Cs (Figure $2 \mathrm{~b}$ ) targets, respectively, both of which were recorded by using a sector type MS/MS instrument.

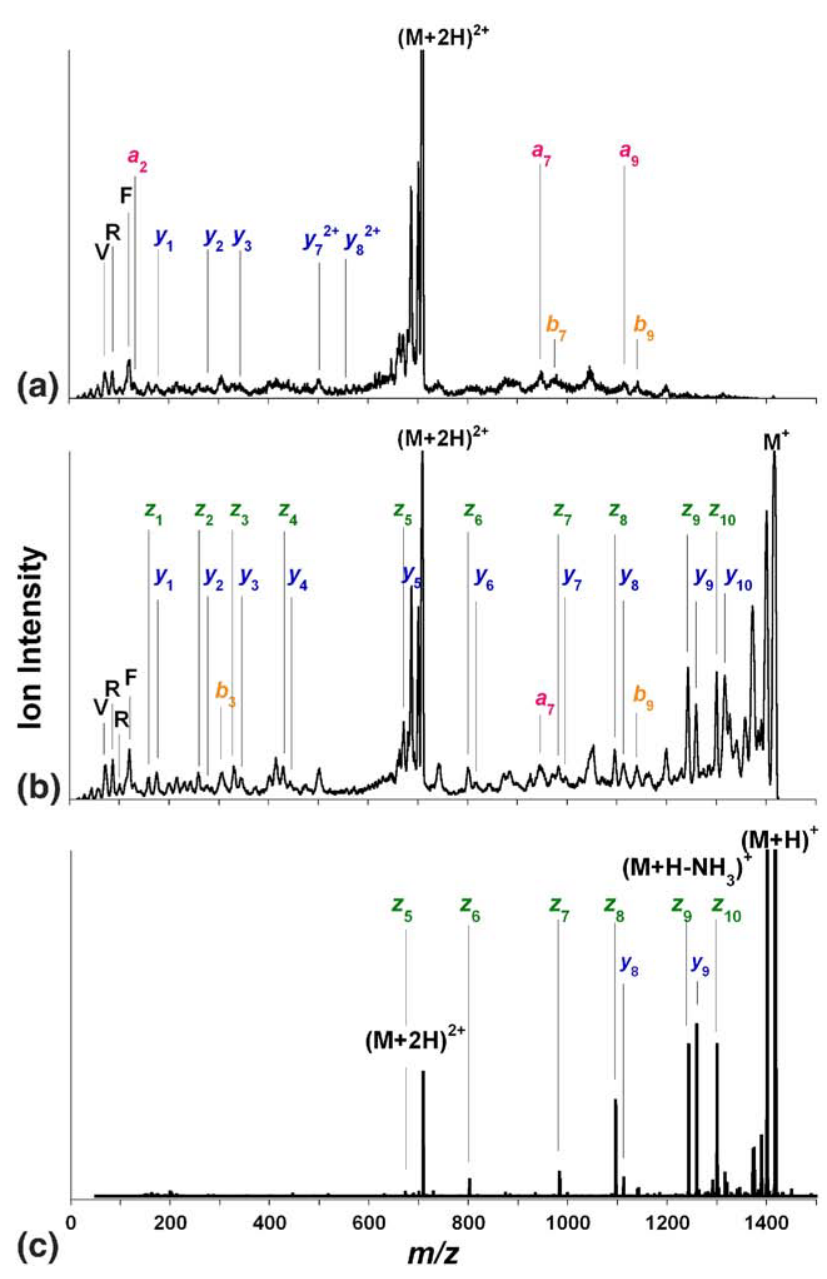

Figure 2. CID spectra of the doubly charged phosphopeptide (1: TGFLT(p)EY(p)VATR) with the Xe (a), and Cs (b) targets and ETD spectrum (c) of the phosphopeptide with fluoranthene monoanion, measured by Finnigan LTQ XL.

Figure $2 \mathrm{c}$ is an ETD spectrum of the phosphopeptide collided with a singly-charged anion, and measured by the Finnigan LTQ XL mass spectrometer. Except the sharp precursor ion peak, the other sharp peaks observed in Figure 2a are located only in the two $\mathrm{m} / \mathrm{z}$ regions, one lower than 150 and the other between 650 and 700 in $\mathrm{m} / \mathrm{z}$. The former are ascribed to the immonium ions which are fragment ions formed from corresponding amino acid residues. The latter are the doublycharged fragment ions formed by losing a side chain from the precursor ions. Although several small and broad peaks are observed in both $\mathrm{m} / \mathrm{z}$ regions lower and higher than that of the precursor ions, series of peaks ascribable to backbone cleavage of the peptide sequence are not observed. While CAD spectra using 4-sector MS/MS instruments reported by Biemann and Martin [47] and Fenselau and coworkers [48] provided sharp peaks assigned as a-type ions, our spectrum using 3-sector (EBE) instrument provided broad peaks due to kinetic energy releases. On the other hand, as seen in 
Figure $2 b$, when the Cs target is employed, many sharp peaks are observed in $\mathrm{m} / \mathrm{z}$ regions both lower and higher than that of the precursor ions, accompanied by the ions observed in the CID spectra measured with the Xe target. The most intense fragment peaks are the charge reduced one with the loss of small radical, neutrals and side chains. While the loss $\mathrm{H}_{2}$ and $\mathrm{H}_{2} \mathrm{O}$ were supposed in the previous paper [40], $\mathrm{H}$ and $\mathrm{NH}_{3}$ loss were reported by electron capture induced dissociation by Hvelplund and coworkers [36, 37]. $m / z$ values of these peaks cannot be confirmed within $\pm 1 \mathrm{u}$ accuracy due to the peak broadening caused by the kinetic energy release. Small but clear peaks of $z$ - and $\mathrm{y}$-type ions are observed as a series in Figure $2 \mathrm{~b}$ whose $m / z$ values are evaluated from their center $m / z$ values of the respective peaks. These $m / z$ values are tabulated in the third column of Table 1 for z-type ions. Except for $z_{5}$, the $m / z$ values agree with those of the series of $z$-type for which neither phosphate group is lost. The large shift of $z_{5}$ is supposed due to peak-overlapping with doubly charged fragment ions. The series of the $z$ - and $y$-type ions are the most intense fragment ions among other types of backbone fragment ions and all the $z$ - and $y$-type ions are observed in the series.

The common features found in HE-CID between the $\mathrm{Xe}$ and $\mathrm{Cs}$ targets are due to the presence of the immonium ions, the doubly charged fragment ions with loss of side-chain, and the broad peaks due to $a_{7}$ and $a_{9}$ ions are observed at $\mathrm{m} / \mathrm{z} 947$ and 1114. Those ions observed in the CID spectra with the Xe target are supposed to result from the high-energy collisionally activated dissociation (HE-CAD). Thus, the same ions observed in the CID spectra with the Cs target are considered to indicate that HE-CAD processes take place also with the Cs target. The charge-reduced ions that were not observed with the Xe target are predominant in the CID spectrum with the Cs target and are supposed to be formed as a result of the high-energy electron-transfer-dissociation (HE-ETD). From the large difference of the spectra that occurred upon interchang-

Table 1. The values of $m / z$ observed for the $z$-type ions produced from the doubly-phosphorylated peptide TGFLT(p)EY(p)VATR and detected in both CID spectrum using the Cs target and ETD spectrum using fluoranthene (F.) anion. The values for $\Delta m / z$ are the differences between the calculated and measured $m / z$ values

\begin{tabular}{cccccr}
\hline Fragment & $\begin{array}{c}m / z \\
\text { (calculated) }\end{array}$ & $\begin{array}{c}m / z \\
\text { (Cs) }\end{array}$ & $\begin{array}{c}\Delta m / z \\
\text { (Cs) }\end{array}$ & \multicolumn{1}{c}{$\begin{array}{c}m / z \\
\text { (F.) }\end{array}$} & $\begin{array}{c}\Delta m / z \\
\text { (F.) }\end{array}$ \\
\hline \hline$z_{1}$ & 159.10 & 158.8 & -0.3 & & \\
$z_{2}$ & 260.15 & 259.2 & -0.9 & & \\
$z_{3}$ & 331.19 & 330.9 & -0.3 & & \\
$z_{4}$ & 430.25 & 429.7 & -0.6 & & \\
$z_{5}$ & 673.28 & 671.7 & -1.6 & 673.3 & 0.0 \\
$z_{6}$ & 802.33 & 801.6 & -0.7 & 802.3 & -0.0 \\
$z_{7}$ & 983.34 & 983.1 & -0.2 & 983.3 & -0.0 \\
$z_{8}$ & 1096.40 & 1096.3 & -0.1 & 1096.3 & -0.1 \\
$z_{9}$ & 1243.49 & 1243.5 & -0.0 & 1243.3 & -0.2 \\
$z_{10}$ & 1300.51 & 1300.9 & 0.4 & 1300.4 & -0.1 \\
\hline
\end{tabular}

ing the target species Xe and Cs, it is concluded that the HE-ETD process provided the ions only observed with the Cs target, and HE-ETD is a process much more effective than HE-CAD with the Cs target. At the same time, it can be said that it is not possible to identify the peptide sequence only from the CID spectrum with the Xe target because random backbone cleavages do not occur in HE-CAD. On the contrary to this, in the CID spectra with the Cs target, the chargereduced ions associated with the backbone cleavage and those with the loss of small neutrals are dominantly produced by HE-ETD. Since the whole series of z-type and $y$-type ions are observed without a loss of any phosphate group, it is possible to confirm the amino acid sequence and the position of the phosphorylation only by the HE-ETD process using the Cs target.

The spectrum feature of LE-ETD with fluoranthene anion shown in Figure 2c is significantly different from the CID spectra measured upon high-energy collision. Sharp peaks of the $z$-type ions without a loss of the phosphate group are clearly observed, and $\pm 0.2 \mathrm{u}$ accuracy of the $m / z$ value is accomplished in LE-ETD as is shown in the sixth column in Table 1. Charge reduced ions and those with loss of small neutrals are dominant in higher mass region of Figure $2 c$ as is the case with HE-CID using Cs target. In contrast to the HE-CID spectrum using the Cs target, the peak intensity in the lower $m / z$ region is weak, and z-type ions with lower masses than $z_{4}$ are not observed.

In the LE-ETD spectrum shown in Figure 2c, chargereduced ions and those that have lost small neutrals prevail. In the spectrum, the z-type ions with the phosphate group undetached are clearly observed. The $y_{8}$ and $y_{9}$ ion peaks are also observed. The $m / z$ values of these peaks show a good agreement with the calculated ones as shown in the sixth column of Table 1. Since the peptide has arginine at its $\mathrm{C}$-terminal and the side chain of the arginine possesses an electric charge, the observation of the $z$-type and $y$-type ions is reasonable and consistent with Figure 2b, measured by HE-ETD technique using the $\mathrm{Cs}$ target. The agreement between LE-ETD and HE-ETD indicates that the dissociation mechanism of the charge-reduced ions formed from electron-transfer is similar in spite of significantly different collision energies available in electron-transfer. HE-ETD provided all of the z-type ions as shown in Figure $2 \mathrm{~b}$, though $z$-type ions of masses lower than $z_{4}$ are not observed in the LE-ETD spectrum. On the basis of the LE-ETD spectrum alone, therefore, it is not possible to confirm the complete peptide sequence. On the contrary to this, although the peak widths are broad because of the larger kinetic energies of the fragment ions, small but clear peaks corresponding to all of the z-type ions are observed by HE-ETD without loss of any phosphate groups. It is possible to confirm the amino acid sequence and position of the phosphorylation only by the HE-ETD spectra measured with the Cs target. 


\section{CID Spectra Using the Cs Target Measured for Three Different Amino Acids Phosphorylated}

The CID spectra of the doubly charged phosphopeptides of $[\mathrm{M}+2 \mathrm{H}]^{2+}$ of $2: \mathrm{M}=($ YGGMHRQES(p)VDC), $3: \mathrm{M}=$ (YGGMHRQET(p)VDC), and 4: $\mathrm{M}=($ YGGMHRQEY(p) VDC) measured with the Cs target are shown in Figure 3a, $b$, and c, respectively. These peptides are different only in the amino acid residue phosphorylated. Spectral features are very similar to each other. Most intense chargereduced peaks observed in the highest $\mathrm{m} / \mathrm{z}$ regions in each spectrum are presumed to arise from loss of small radicals, molecules, and side chains. Immonium ions are observed in the $\mathrm{m} / \mathrm{z}$ region lower than 150, similar to Figure 2a and $\mathrm{b}$. Except for the immonium ions, sharp peaks are few in the $\mathrm{m} / \mathrm{z}$ region lower than that of the precursor ion. Small but well-resolved peaks are observed as a series in Figure 3a, b, and c. The values for $\mathrm{m} / \mathrm{z}$ evaluated from a center $\mathrm{m} / \mathrm{z}$ value of each peak are tabulated in Table 2. The peaks of $z_{7}$ and $c_{8}$ ions in Figure $3 c$ cannot be discriminated because of a small difference of $\mathrm{m} / \mathrm{z}$ values as shown in Table 2 . The c-type ions produced via $\mathrm{N}-\mathrm{C} \alpha$ backbone cleavage are most intense regardless

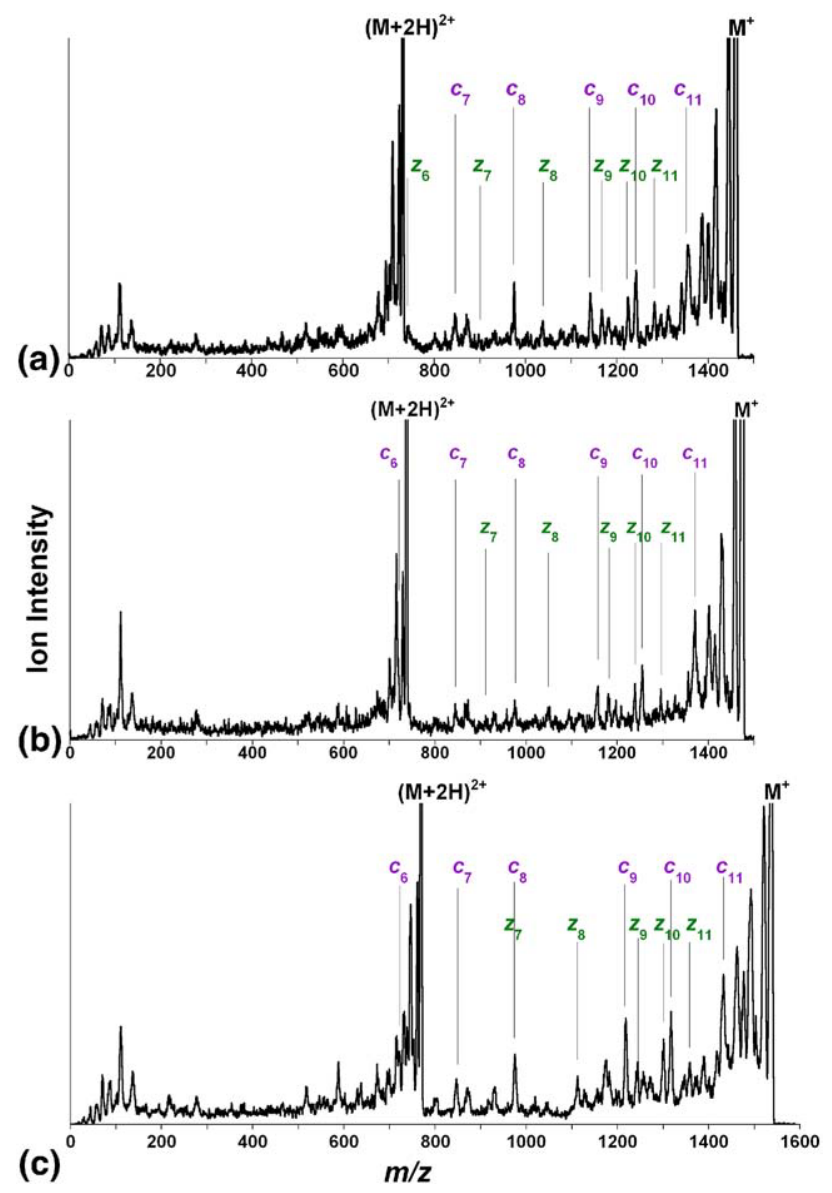

Figure 3. CID spectra of the doubly charged phosphopeptide (2: YGGMHRQES(p)VDC) (a), (3: YGGMHRQET(p)VDC) (b), and (4: YGGMHRQEY(p)VDC) (c) with the Cs target. Fragment peaks and their intensities are similar irrespective of the amino acids phosphorylated. of the phosphopeptides 2 to 4 . While the $m / z$ values for $c_{6}$ to $c_{8}$ are identical in all the spectra of Figure 3 since the corresponding fragments do not include the amino acid phosphorylated, those of $c_{9}$ to $c_{11}$ and $z_{6}$ to $z_{11}$ differ from spectrum to spectrum because these fragments include an amino acid phosphorylated. Based on the shift of the $m / z$ values for $c_{9}$ to $c_{11}$ and $z_{6}$ to $z_{11}$, all of which depend on the amino acid phosphorylated, these $\mathrm{m} / \mathrm{z}$ values are definitely assigned to the $c$-type and $z$-type ions formed by via $\mathrm{N}-\mathrm{C} \alpha$ backbone cleavage for any of the phosphopeptides 2 through 4 . The abundances of $z$-type ions $\left(z_{7} \sim z_{11}\right)$ are lower than those of the $c$-type ions. Relative ion intensities of both $c$ - and $z$-type ions are similar regardless of the phosphopeptides 2 to 4 as shown in Figure 3. Several peaks observed in the $m / z$ region located higher than the $\mathrm{m} / \mathrm{z}$ values for the $c_{11}$ ions, whose $\mathrm{m} / \mathrm{z}$ values showed the same shift from the respective largest charge reduced peak, are assigned to the charge-reduced ions accompanied by a loss of side chain of the corresponding amino acid residues. Comparatively large differences in $\mathrm{m} / \mathrm{z}$ values among $z_{6}$ in $2, c_{7}$ in 3, and $c_{6}$ in 4 given in Table 2 are supposed due to peak-overlapping with other ions. While all of the $z$-type ions are observed in Figure $2 b$, the peaks of from $c_{1}$ to $c_{5}$ and from $z_{1}$ to $z_{5}$ of 2,3 , and 4 are not observed in Figure 3 because of insufficient intensities.

The abundant presence of $c$ - and z-type ions in the higher mass region is explained by taking the position of the arginine, which may have an electric charge on its side-chain, into an account. The observation agreed with the supposition that the charge-reduced ion having the arginine does not induce a $\mathrm{H}$ atom transfer to the backbone [30]. From the $c$ - and z-type ions, it is possible to confirm the amino acid sequence and the position of the phosphorylation for any of the amino acid phosphorylated through the CID spectra with the Cs target as a result of HE-ETD.

\section{Comparison of the HE-ETD Using the Alkali Metal Target with the LE-ETD Using the Anion Measured for Three Different Amino Acids Phosphorylated}

The LE-ETD spectra of the doubly charged phosphopeptides of $[\mathrm{M}+2 \mathrm{H}]^{2+}$ of 2,3 , and 4 measured with fluoranthene anion are shown in Figure $4 a, b$, and c, respectively. Spectral features are very similar to each other, as do those of the CID spectra using the Cs target. Most intense charge-reduced peaks observed in the highest $m / z$ regions in each spectrum arise from $\mathrm{H}$ loss and small radicals. The $c$-type ( $c_{5}$ to $\left.c_{11}\right)$ and $z$-type ( $c_{7}$ to $c_{11}$ ) ions produced via $\mathrm{N}-\mathrm{C} \alpha$ backbone cleavage are most intense among other types of backbone fragment ions regardless of the phosphopeptides 2 to 4 , as shown in Figure 4. While relative abundances of the respective $c$-type and $z$-type ions by the LE-ETD in Figure $4 a, b$, and $c$ are not same as those by HE-ETD in Figure 3a, b, and $c$, spectral features between the LE-ETD and the HE-ETD are similar for the respective precursors. In 
Table 2. The values of $\mathrm{m} / \mathrm{z}$ observed for the $c$-type and $z$-type ions produced from the doubly-phosphorylated peptides of 2:YGGMHRQES(p)VDC, 3:YGGMHRQET(p)VDC, and 4: YGGMHRQEY(p)VDC, and detected in the CID spectra using the Cs target. $\Delta m / z$ stands for the difference between the calculated and measured values

\begin{tabular}{|c|c|c|c|c|c|c|c|c|c|}
\hline \multirow{2}{*}{$\begin{array}{l}\text { Peptide } \\
\text { fragment }\end{array}$} & \multicolumn{3}{|c|}{ YGGMHROES(p)VDC } & \multicolumn{3}{|c|}{ YGGMHRQET(p)VDC } & \multicolumn{3}{|c|}{ YGGMHROEY(p)VDC } \\
\hline & $\mathrm{m} / \mathrm{z}$ (cal.) & $m / z(\mathrm{Cs})$ & $\Delta m / z(\mathrm{Cs})$ & $\mathrm{m} / \mathrm{z}$ (cal.) & $m / z(\mathrm{Cs})$ & $\Delta m / z(\mathrm{Cs})$ & $m / z$ (cal.) & $m / z(\mathrm{Cs})$ & $\Delta m / z(C s)$ \\
\hline$c_{6}$ & 719.34 & & & 719.34 & 719.4 & 0.1 & 719.34 & 721.4 & 1.9 \\
\hline$z_{6}$ & 744.20 & 741.8 & -2.4 & 758.22 & & & 820.23 & & \\
\hline$c_{7}$ & 847.40 & 846.0 & -1.4 & 847.40 & 845.3 & -2.1 & 847.40 & 847.2 & -0.2 \\
\hline$z_{7}$ & 900.30 & 900.1 & -0.2 & 914.32 & 915.6 & 1.3 & 976.34 & 975.3 & -1.0 \\
\hline$c_{8}$ & 976.44 & 974.8 & -1.6 & 976.44 & 974.9 & -1.5 & 976.44 & 975.3 & -1.1 \\
\hline$z_{8}$ & 1037.36 & 1037.5 & 0.1 & 1051.38 & 1051.6 & 0.2 & $1,113.39$ & 1113.0 & -0.4 \\
\hline$c_{9}$ & 1143.44 & 1141.8 & -1.6 & 1157.46 & 1157.1 & -0.4 & 1219.47 & 1218.7 & -0.8 \\
\hline$z_{9}$ & 1168.40 & 1167.0 & -1.4 & 1182.42 & 1180.5 & -1.9 & 1244.44 & 1244.6 & 0.2 \\
\hline$z_{10}$ & 1225.43 & 1224.5 & 0.9 & 1239.44 & 1238.9 & -0.5 & 1301.16 & 1301.6 & 0.4 \\
\hline$c_{10}$ & 1242.51 & 1241.8 & -0.7 & 1256.52 & 1254.9 & -1.6 & 1318.54 & 1317.7 & -0.8 \\
\hline$z_{11}$ & 1282.45 & 1282.3 & -0.1 & 1296.46 & 1295.6 & -0.9 & 1358.48 & 1358.2 & -0.3 \\
\hline$c_{11}$ & 1357.54 & 1355.5 & -2.0 & 1371.55 & 1370.6 & -1.0 & 1433.57 & 1432.1 & -1.5 \\
\hline
\end{tabular}

HE-ETD of the present work, the speed of the doubly charged ion with $\mathrm{m} / \mathrm{z}$ of $750 \mathrm{u}$ accelerated by $5 \mathrm{kV}$ is $3.6 \times$ $10^{4} \mathrm{~m} / \mathrm{s}$ [23]. By assuming that the interaction region is twice of $6.8 \times 10^{-10} \mathrm{~m}$ of the length at the Landau-Zener potential crossing evaluated for the Cs target [39], the

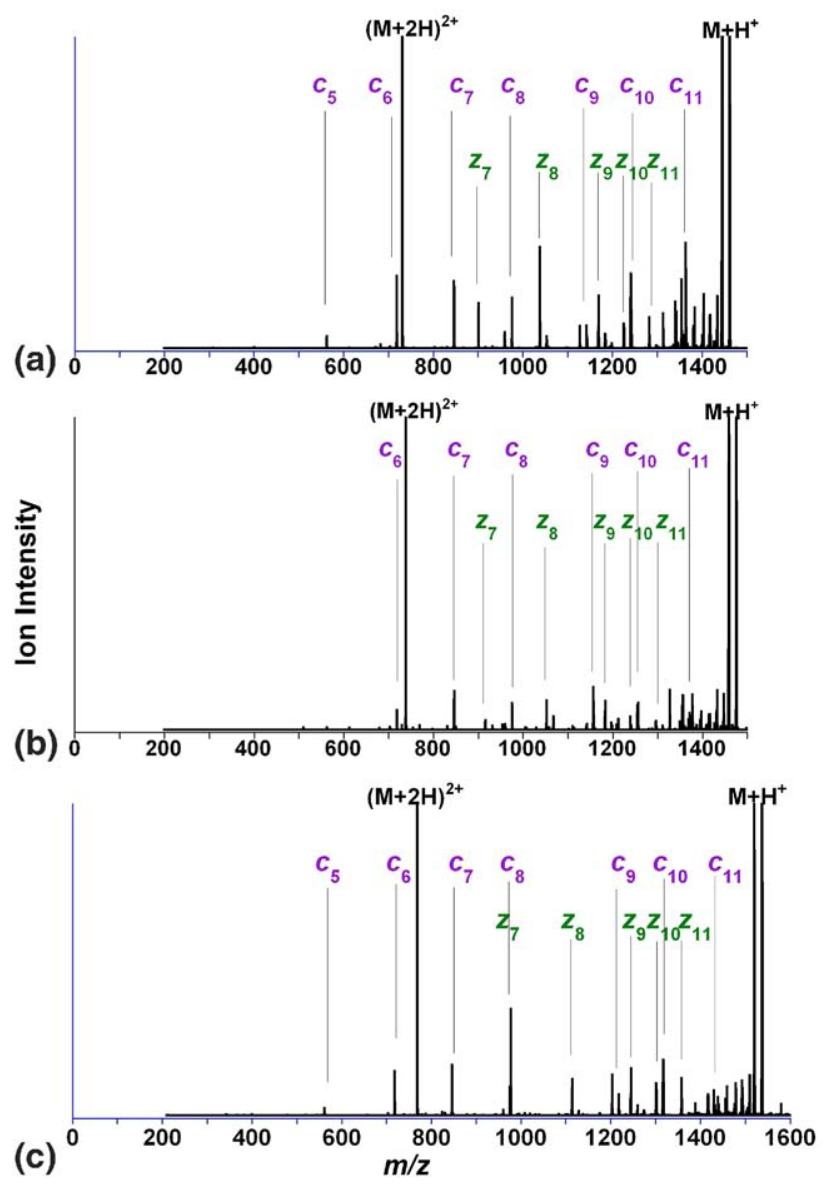

Figure 4. ETD spectra of the doubly charged phosphopeptide (2: YGGMHRQES(p)VDC) (a), (3: YGGMHRQET(p)VDC) (b), and (4: YGGMHRQEY(p)VDC) (c) with the fluoranthene anion. Fragment peaks and their intensities are similar irrespective of the amino acids phosphorylated. interaction time between the collision partners is estimated to be $3.8 \times 10^{-14} \mathrm{~s}$. A period for dissociation was estimated from the length of $230 \mathrm{~cm}$ between the exit of the target chamber and the entrance of the MS-II is 6.5 $\mu \mathrm{s}$. This period is much shorter than the reaction time in the LE-ETD. Although the electron binding energies of $0.63 \mathrm{eV}$ to be the electron affinity of the fluoranthene is much smaller than that of $3.89 \mathrm{eV}$ of the ionization energy of the Cs, the difference of internal energies depositing to the charge reduced species between HEETD and LE-ETD is affected by charge-induced dipole interaction in the entrance channel of the electrontransfer as discussed in the previous papers [38, 39]. While these differences exist, the similar result between the HE-ETD and the LE-ETD is supposed due to the electron-transfer process of bound electrons in both processes.

\section{Conclusions}

The HE collision-induced dissociation (HE-CID) spectra of the doubly-protonated phosphopeptide $(\equiv[\mathrm{M}+$ $2 \mathrm{H}]^{2+}$ ) of $1,2,3$, and 4 were measured with the $\mathrm{Xe}$ and Cs targets. While abundant product ions with the Xe target were immonium ions and doubly-charged fragment ions, those with the Cs target were the chargereduced fragment ions, whose relative abundances were about 10 times larger than those of the immonium ions and doubly-charged fragment ions. The difference between the $\mathrm{Xe}$ and the Cs target indicates that collisions with the Cs target allow much more effective ETD than CAD. In the CID spectra with the Cs target, $c$-type and $z$-type ions produced via backbone cleavages were clearly observed for all the peptides. For 1, in particular, the $z$-type ions from $z-1$ to $z-11$ were clearly observed. These fragment ions provided information on the complete peptide sequence and the position of the phosphorylation. In the spectra of LE-ETD, no chargereduced fragment ions were observed in mass region lower than that of the precursor ion. HE-ETD provided 
peptide sequences in full mass range without losing phosphate groups. The CID spectrum of $\mathbf{1}$ indicated that HE-ETD could reveal the position of phosphorylation, irrespective of the number of phosphorylation.

The CID spectra of $\mathbf{2}, \mathbf{3}$, and $\mathbf{4}$ showed a very similar trend as do those of $\mathbf{1}$, which provided the $c$-type ions from $c_{7}$ to $c_{11}$ and the z-type ions from $z_{7}$ to $z_{11}$ formed via $\mathrm{N}-\mathrm{C} \alpha$ bond cleavage without a loss of the phosphate group. These results indicate that HE-ETD can provide us information on the peptide sequence regardless of a kind of amino acid phosphorylated. The finding that only $z$-type ions were observed for $\mathbf{1}$ was a large difference between 1 and a group of 2-4 and was explained by the position of arginine, whose side chain has the largest proton affinity among amino acids.

\section{Acknowledgments}

The authors acknowledge support for this work by Grants-in-Aid for Research no. 0925200071 for Promoting Technological Seeds from the Japan Science and Technology Agency and by a special research grant from AIST research grant.

\section{References}

1. Manning, G.; Plowman, G. D.; Hunter, T.; Sudarsanam, S. Evolution of Protein Kinase Signaling from Yeast to Man. Trends Biochem. Sci. 2002, 27, 514-520.

2. Ishida, A.; Kameshita, I.; Sueyoshi, N.; Taniguchi, T.; Shigeri, Y. Recent Advances in Technologies for Analyzing Protein Kinases. J. Pharmacol. Sci. 2007, 103, 5-11.

3. Fenn, J. B.; Mann, M.; Meng, C. K.; Wong, S. F.; Whitehouse, C. M. Electrospray Ionization for Mass Spectrometry of Large Biomolecules. Science 1989, 246, 64-71.

4. Boersema, P. J.; Mohammed, S.; Heck, A. J. R. Phosphopeptide Fragmentation and Analysis by Mass Spectrometry. J. Mass Spectrom. 2009, $44,861-878$

5. Zubarev, R. A.; Kelleher, N. L.; McLafferty, F. W. Electron Capture Dissociation of Multiply Charged Protein Cations. A Nonergodic Process. J. Am. Chem. Soc. 1998, 120, 3265-3266.

6. Zubarev, R. A.; Kruger, N. A.; Fridriksson, E. K.; Lewis, M. A.; Horn, D. M.; Carpenter, B. K.; McLafferty, F. W. Electron Capture Dissociation of Gaseous Multiply-Charged Proteins is Favored at Disulfide Bonds and Other Sites of High Hydrogen Atom Affinity. J. Am. Chem. Soc. 1999, 121, 2857-2862.

7. Zubarev, R. A.; Haselmann, K. F.; Budnik, B.; Kjeldsen, F.; Jensen, F. Towards an Understanding of the Mechanism of Electron-Capture Dissociation: A Historical Perspective and Modern Ideas. Eur. J. Mass Spectrom. 2002, 8, 337-349.

8. Zubarev, R. A. Reactions of Polypeptide Ions with Electrons in the Gas Phase. Mass Spectrom. Rev. 2003, 22, 57-77.

9. Syka, J. E. P.; Coon, J. J.; Schroeder, M. J.; Shabanowitz, J.; Hunt, D. F. Peptide and Protein Sequence Analysis by Electron Transfer Dissociation Mass Spectrometry. Proc. Natl. Acad. Sci. U.S.A. 2004, 101, 9528-9533.

10. Coon, J. J.; Syka, J. E. P.; Schwartz, J. C.; Shabanowitz, J.; Hunt, D. F. Anion Dependence in the Partitioning between Proton and Electron Transfer in Ion. Int. J. Mass Spectrom. 2004, 236, 33-42.

11. Roepstorff, P.; Fohlman, J. Proposal for a Common Nomenclature for Sequence Ions in Mass Spectra of Peptides. Biomed. Mass Spectrom. 1984, 11, 601-601

12. Biemann, K. Contributions of Mass Spectrometry to Peptide and Protein Structure. Biomed. Environ. Mass Spectrom. 1988, 16, 99-111.

13. Stensballe, A.; Jensen, O. N.; Olsen, J. V.; Haselmann, K. F.; Zubarev, R. A. Electron Capture Dissociation of Singly and Multiply Phosphorylated Peptides. Rapid Commun. Mass Spectrom. 2000, 14, 1793-1800.

14. Shi, S. D. H.; Hemling, M. E.; Carr, S. A.; Horn, D. M.; Lindh, I.; McLafferty, F. W. Phosphopeptide/Phosphoprotein Mapping by Electron Capture Dissociation Mass Spectrometry. Anal. Chem. 2001, 73, 19-22.

15. Simons, J. Mechanisms for S-S and N-C $\alpha$ Bond Cleavage in Peptide ECD and ETD Mass Spectrometry. Chem. Phys. Lett. 2010, 484, 81-95.

16. Turecek, F.; Syrstad, E. A.; Seymour, J. L.; Chen, X. H.; Yao, C. X. Peptide Cation-Radicals. A Computational Study of the Competition between Peptide N-C $\alpha$, Bond Cleavage and Loss of the Side Chain in the [GlyPhe$\left.\mathrm{NH}_{2}+2 \mathrm{H}\right]^{+} \cdot$ Cation-Radical. J. Mass Spectrom. 2003, 38, 1093-1104.

17. Turecek, F. N-C $\alpha$ Bond Dissociation Energies and Kinetics in Amide and Peptide Radicals is the Dissociation a Non-Ergodic Process? J. Am. Chem. Soc. 2003, 125, 5954-5963.
18. Turecek, F.; Syrstad, E. A. Mechanism and Energetics of Intramolecular Hydrogen Transfer in Amide and Peptide Radicals and Cation Radicals. J. Am. Chem. Soc. 2003, 125, 3353-3369.

19. Syrstad, E. A.; Turecek, F. Toward a General Mechanism of Electron Capture Dissociation. J. Am. Soc. Mass Spectrom. 2005, 16, 208-224.

20. Chen, X. H.; Turecek, F. The Arginine Anomaly: Arginine Radicals are Poor Hydrogen Atom Donors in Electron Transfer Induced Dissociations. J. Am. Chem. Soc. 2006, 128, 12520-12530.

21. Li, X.; Lin, C.; Han, L.; Costello, C. E.; O'Connor, P. B. Charge Remote Fragmentation in Electron Capture and Electron Transfer Dissociation. J. Am. Soc. Mass Spectrom. 2010, 21, 646-656.

22. Zhang, Z. Prediction of Electron-Transfer/Capture Dissociation Spectra of Peptides. Anal. Chem. 2010, 82, 1990-2005.

23. Hayakawa, S. Charge Inversion Mass Spectrometry: Dissociation of Resonantly Neutralized Molecules. J. Mass Spectrom. 2004, 39, 111-135.

24. Hayakawa, S. Internal Energy Distribution in Charge Inversion Mass Spectrometry using Alkali Metal Targets. Int. J. Mass Spectrom. 2001, 212, 229-247.

25. Hayakawa, S.; Endoh, H.; Arakawa, K.; Morishita, N. Dissociation Mechanism of Electronically Excited $\mathrm{C}_{3} \mathrm{H}_{4}$ Isomers by Charge Inversion Mass Spectrometry. Int. J. Mass Spectrom. 1997, 171, 209-214.

26. Hayakawa, S.; Endoh, H.; Arakawa, K.; Morishita, N.; Sugiura, T. Discrimination of $\mathrm{C}_{3} \mathrm{H}_{4}^{+}$Isomeric Ions by Charge Inversion Mass Spectrometry using an Alkali Metal Target. Int. J. Mass Spectrom. Ion Processes 1995, 151, 89-95.

27. Sasaki, T.; Matsubara, H.; Hayakawa, S. Differences between Collisionally Activated and Electron-Transfer Dissociations found for $\mathrm{CH}_{2} \mathrm{X}_{2}$ $(\mathrm{X}=\mathrm{Cl}, \mathrm{Br}$, and I) by using Alkali-Metal Targets. J. Mass Spectrom. 2008, $43,1679-1685$.

28. Hayakawa, S.; Hashimoto, M.; Matsubara, H.; Turecek, F. Dissecting the Proline Effect: Dissociations of Proline Radicals Formed by Electron Transfer to Protonated Pro-Gly and Gly-Pro Dipeptides in the Gas Phase. J. Am. Chem. Soc. 2007, 129, 7936-7949.

29. Hayakawa, S.; Matsubara, H.; Kawamura, Y.; Iwamoto, K. Definitive Evidence for the Existence of Isomeric Chlorophenyl Radicals $\left(\mathrm{C}_{6} \mathrm{H}_{4} \mathrm{Cl}\right)$ from Charge Inversion Mass Spectrometry and DFT Calculations. Int. J. Mass Spectrom. 2007, 262, 220-231.

30. Hayakawa, S.; Matsubara, H.; Panja, S.; Hvelplund, P.; Nielsen, S. B.; Chen, X.; Turecek, F. Experimental Evidence for an Inverse Hydrogen Migration in Arginine Radicals. J. Am. Chem. Soc. 2008, 130, 7645-7654.

31. Turecek, F.; Yao, C.; Fung, Y. M. E.; Hayakawa, S.; Hashimoto, M.; Matsubara, H. Histidine-Containing Radicals in the Gas Phase. J. Phys. Chem. B 2009, 113, 7347-7366.

32. Hvelplund, P.; Liu, B.; Nielsen, S. B.; Tomita, S. Electron Capture Induced Dissociation of Peptide Dications. Int. J. Mass Spectrom. 2003, 225, 83-87.

33. Hvelplund, P.; Liu, B.; Nielsen, S. B.; Tomita, S.; Cederquist, H.; Jensen, J.; Schmidt, H. T.; Zettergren, H. Electron Capture and Loss by Protonated Peptides and Proteins in Collisions with C-60 and Na. Eur. Phys. JD 2003, 22, 75-79.

34. Chakraborty, T.; Holm, A. I. S.; Hvelplund, P.; Nielsen, S. B.; Poully, J. C.; Worm, E. S.; Williams, E. R. On the Survival of Peptide Cations After Electron Capture: Role of Internal Hydrogen Bonding and Microsolvation. J. Am. Soc. Mass Spectrom. 2006, 17, 1675-1680.

35. Hvelplund, P.; Liu, B.; Nielsen, S. B.; Panja, S.; Poully, J. C.; Stochkel, K Electron Capture Induced Dissociation of Peptide Ions: Identification of Neutral Fragments from Secondary Collisions with Cesium Vapor. Int. J. Mass Spectrom. 2007, 263, 66-70.

36. Holm, A. I. S.; Hvelplund, P.; Kadhane, U.; Larsen, M. K.; Liu, B.; Nielsen, S. B.; Panja, S.; Pedersen, J. M.; Skrydstrup, T.; Stochkel, K.; Williams, E. R.; Worm, E. S. On the Mechanism of Electron-CaptureInduced Dissociation of Peptide Dications from N-15-Labeling and Crown-Ether Complexation. J. Phys. Chem. A 2007, 111, 96419643.

37. Bernigaud, V.; Cederquist, H.; Haag, N.; Holm, A. I. S.; Huber, B. A.; Hvelplund, P.; Kadhane, U.; Larsen, M. K.; Manil, B.; Nielsen, S. B. Panja, S.; Ptasińska, S.; Rangama, J.; Reinhed, P.; Schmidt, H. T.; Streletskii, A. V.; Støchkel, K.; Worm, E. S.; Zettergren, H. Electron Capture-Induced Dissociation of AK Dipeptide Dications: Influence of Ion Velocity, Crown-Ether Complexation and Collision Gas. Int. J. Mass Spectrom. 2008, 276, 77-81.

38. Hayakawa, S.; Kitaguchi, A.; Kameoka, S.; Toyoda, M.; Ichihara, T. Differences Between the Internal Energy Depositions Induced by Collisional Activation and by Electron Transfer of $\mathrm{W}(\mathrm{CO})_{6}^{2+}$ Ions on Collision with Ar and K Targets. J. Chem. Phys. 2006, 124, 224320.

39. Hayakawa, S.; Minami, K.; Iwamoto, K.; Toyoda, M.; Ichihara, T. Nagao, H. Potential Crossing Position in Electron Transfer of a Doubly Charged Ion and an Alkali Metal Target Measured using Thermometer Molecule $\mathrm{W}(\mathrm{CO})_{6}$. Int. J. Mass Spectrom. 2007, 266, 122-128.

40. Hayakawa, S.; Hashimoto, M.; Nagao, H.; Awazu, K.; Toyoda, M. Ichihara, T.; Shigeri, Y. Study of the Dissociation of a Charge-Reduced Phosphopeptide Formed by Electron Transfer from an Alkali Metal Target. Rapid Commun. Mass Spectrom. 2008, 22, 567-572.

41. Fujisawa, H. Regulation of the Activities of Multifunctional $\mathrm{Ca}^{2+}$ J. Biochem. 2001, 129, 193-199.

42. Soderling, T. R.; Chang, B.; Brickey, D. Cellular Signaling through Multifunctional $\mathrm{Ca}^{2+}$. J. Biol. Chem. 2001, 276, 3719-3722.

43. Alexander, S. P. H.; Mathie, A.; Peters, J. A. Guide to Receptors and Channels (GRAC), 4th Edition. Br. J. Pharmacol. 2009, 158, S1-S239. 
44. Wakamiya, T.; Togashi, R.; Nishida, T.; Saruta, K.; Yasuoka, J.; Kusumoto, S.; Aimoto, S.; Kumagaye, K. Y.; Nakajima, K.; Nagata, K. Synthetic Study of Phosphopeptides Related to Heat Shock Protein HSP27. Bioorg. Med. Chem. 1997, 5, 135-145.

45. Ishida, A.; Shigeri, Y.; Tatsu, Y.; Endo, Y.; Kameshita, I.; Okuno, S.; Kitani, T.; Takeuchi, M.; Yumoto, N.; Fujisawa, H. Substrate Specificity of $\mathrm{Ca}^{2+}$. J. Biochem. 2001, 129, 745-753.

46. Nagao, H.; Hayakawa, S.; Hashimoto, M.; Iwamoto, K.; Toyoda, M.; Shigeri, Y.; Jitosho, M.; Awazu, K. Development of a Tandem Mass
Spectrometry Instrument for Probing High-Energy Electron Transfer Dissociation. J. Mass Spectrom. Soc. Jpn. 2009, 57, 123-132.

47. Biemann, K.; Martin, S. A. Mass Spectrometric Determination of the Amino Acid Sequence of Peptides and Proteins. Mass Spectrom. Rev. $1987,6,1-75$.

48. Cheng, X. H.; Wu, Z. C.; Fenselau, C.; Ishihara, M.; Musselman, B. D. Interface for a 4-Sector Mass-Spectrometer with a Dual-Purpose Collision Cell-High Transmission at Low to Intermediate Energies. J. Am. Soc. Mass Spectrom. 1995, 6, 175-186. 